\title{
Tracking Management System Designed for the Second-hand Car Based on the RFID Technology
}

\author{
Ling-ling Wei \\ Department of Computer of JiangXi University of technology NanChang JiangXi, 330098,china
}

Keywords: RFID technology, electronic label, second-hand car, monitor

\begin{abstract}
Tracking all services of the second-hand car in order to regulate the management of the second-hand car, then analyzed and designed the second-hand car tracking management system to read and write by the RFID technology, label attached to the car in the system, and real-time record the services, repairs, leases, auctions, replacements and other information to the car, then the information are transferred to the remote computer management center to storage. It is realized the services information automatic collection processing for the second-hand car, tracking and monitor that will benefit the second-hand car, so as to standardize management of the second-hand car, and the maximization of resource sharing, then cost saving.
\end{abstract}

\section{Introduction}

The second-hand car is "second-hand car" or "used car". The second-hand car market as a representative of the automotive aftermarket, huge market value has been attracting the business competition and rapid development. But the second-hand car market development slowly in china, the main problem is security function loss, industry resources disordered configuration, the second-hand car evaluation criterion lack, market unreasonable charges after analysis and comparison. The tracking management system for the second-hand car is real-time record the services, repairs, leases, auctions, replacements of the car, and the information are sent to the remote computer to storage. Information management is made for the second-hand car management normalization and the resource sharing maximization,[1,2].

\section{The RFID technology application advantage}

The Radio Frequency Identification (RFID) technology is a kind of wireless communication technology, and special target recognition and relevant data reading and writing by way of radio signal. The radio signal is transmit the data from the label of the object by tune the electromagnetic field of the radio frequency, then automatic identification and trail the object. The most important advantages of RFID system is non-contact identification, it can reading penetrate through snow, fog, ice, dirt and bar code cannot use harsh environment, and the speed quickly less than 100 milliseconds. The RFID technology application widely,[3,4,5,6,7], the specific applications include the anti-fraud technology of money and product, ID, passport, electronic toll system, patient identification and electronic medical record, logistics management, entrance guard system domestic or wild animal identification, and etc....At present, the development of the RFID technology in China is far behind the United States and Europe, and big efforts to catch up with this "new wave”.

\section{The system overall framework designed and the hardware platform}

With the existing development technology and the advantages of the RFID technology, it is structured the second-hand car tracking management system to solve the problem of the second-hand car, for example ensure deficiency and the rate of resource utilization low.

\subsection{The system overall framework designed}

The system design has three layer structures, it is data acquisition terminal layer, data transmission network layer and data center management layer. The data acquisition terminal 
equipment layer mainly includes the RFID tags, RFID antenna distributed the automobile service places, the fixed RFID reader, the wireless handheld RFID reader and the client. The data transmission network layer includes routers and other network equipment that covered all auto services center. Its main function is transferred, collected and filtered data acquired from the terminal to database. The data center management layer mainly includes the RFID database, system server, data center server and a variety of control system. Its main function is data storage and exchange, and provided external access to query and control for user. Each automobile service center connected with the Internet, realize the information sharing and data exchange, and intelligent identification, tracking, monitoring and management,[8,9,10].

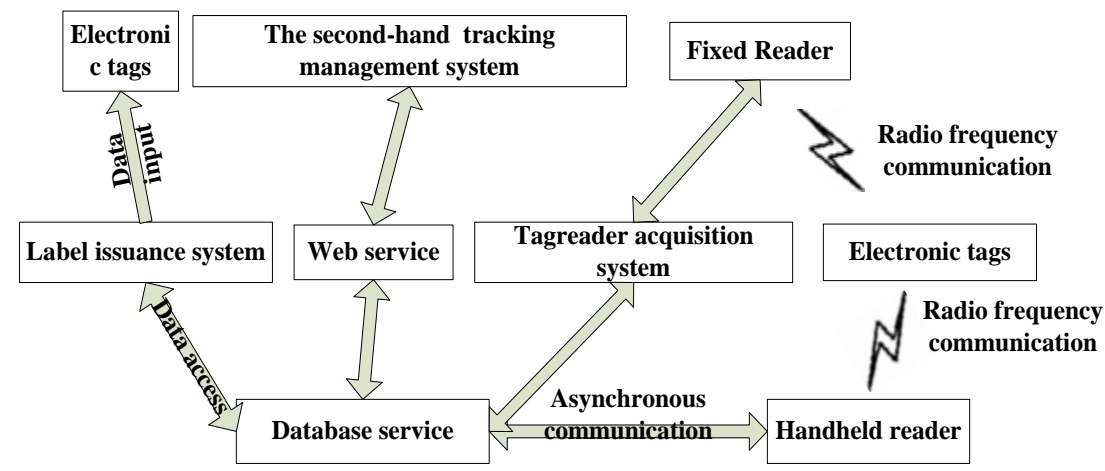

Fig.1 The system framework diagram

\subsection{The system hardware platform}

The system hardware mainly includes the RFID tags, data acquisition terminals and communication equipments, the client and the server computers. Where the RFID tag is the information carrier of the second-hand car and attach it to the car; The data acquisition terminal adopt the fixed reader and the wireless handle reader, the fixed reader can be used alone or integrate with the system, time sharing scan the RFID tags and connected related equipment via a communication interface . The wireless handle reader used alone, and through the wireless LAN carried information to the database, the client is responsible for data information input and query, the server is responsible for data storage, optimizing and so on.

\section{The system software designed}

\subsection{The system work flow}

1) Information write in tag: startup tab issuing system, embedded tags where storage the information of the second-hand car in the car.

2) Information acquire from tag: reading information of the car and display on the client by the RFID reader when the second-hand car driving into a service center.

3) The client data input: the client add received service information according to acquired information of the second-hand, then storage and transmission to the server. 


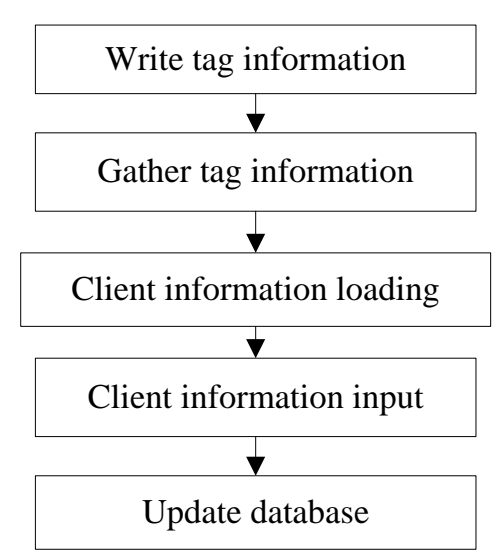

Fig. 2 Business flow chart

\subsection{The function module designed}

The main function modules of the second-hand car tracking management system are system management, car based information, auto service, auto repair, auto rental, car replacement, auto auction. The system management is the management of the system, mainly has department information, post information, user information, permission distribution and others; The based information management of the car has delete, modify, query and other functions.

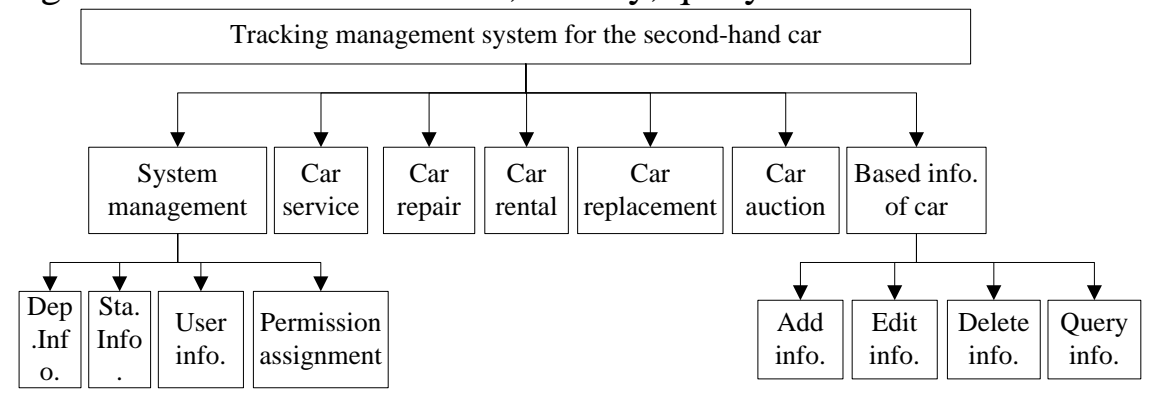

Fig.3 The system module structure diagram

(1) The car service

The car service is mainly managed the common service received by car, its module as follows.

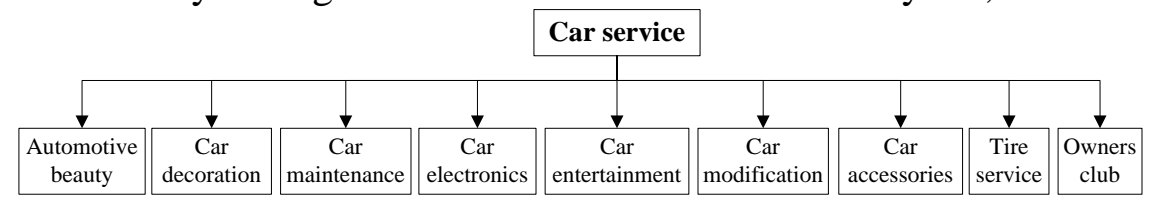

Fig.4 The car service module diagram

(2) The car rental

The car rental is mainly responsible for information management of the car rental, the sub-modules of the car rental as follows.

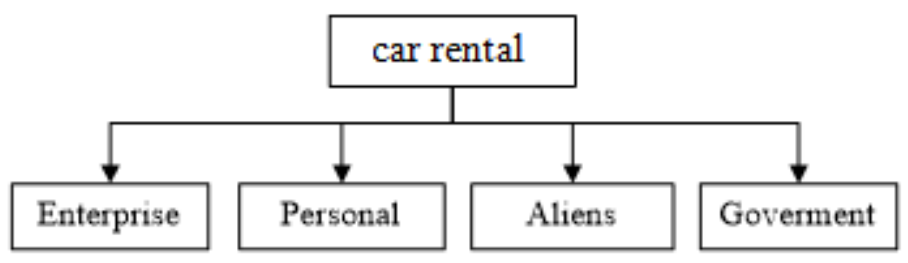

Fig.5 The car rental module diagram

(3) The car replacementThe car replacement is mainly managed data of the new car displaces the second-car throughout whole process, its processing flow as below: 


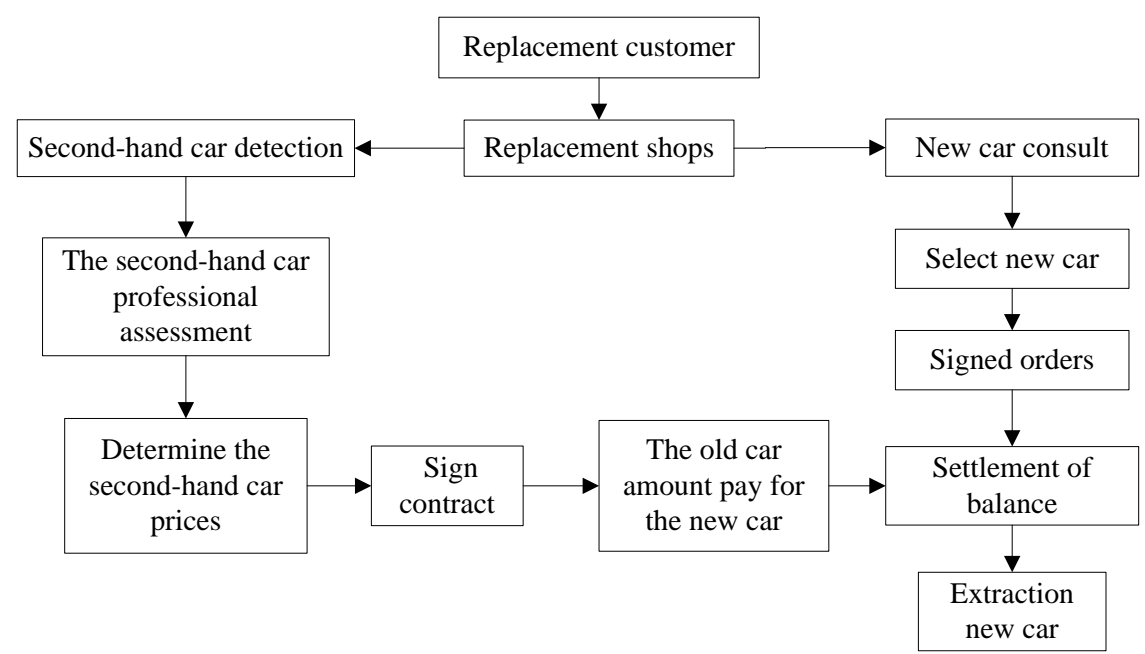

(4) The car auction

Fig.6 The car replacement flow chart

The car auction is mainly responsible for auction information of the second-hand car, the processing procedure as follow:

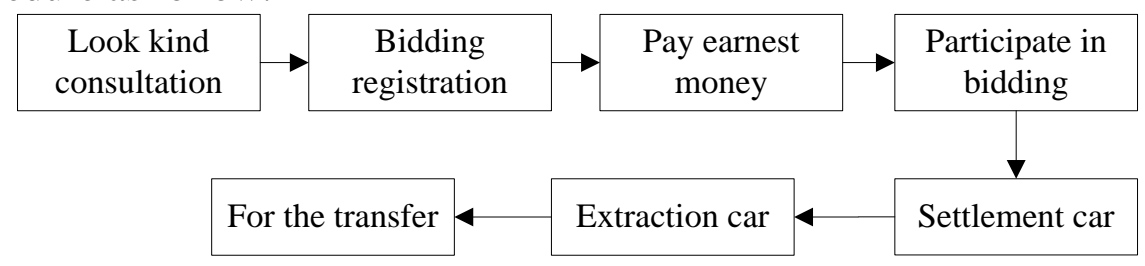

Fig.7 The car auction process chart

\section{Conclusion}

Based on the current of the second-hand car and wide application of the RFID technology, this paper is forwarded apply the RFID technology to the information management of the second-hand car, and studied the service of the second-hand car management system. The tag embedded in the car, real time record the service, repair, lease, auction, replacement of the car received, and transmitted information to remote computer center to storage. Then advantages have:

(1) Effective monitoring and tracking.

The information are transmitted to the computer center, it can monitor and tracking the second-hand car.

(2) Realize information sharing.

The portal of the system into the Internet, then facilitate the view.

(3) Raise the utilization rate of resources.

Information sharing can reduce the resources redundant construction, then saving cost.

(4) Provide decision assistance.

The information of the system is provided decision makers with help.

(5) The RFID technology was applied to the tracking management of second-hand car.

\section{Acknowledgements}

The research work was supported by innovation development project of JiangXi technology University (NO.XJXT1408).

\section{References}

[1]Wu Bosheng,Guo Dianchen.The Development Status and the Business Strategies Adjustment of Domestic Second-hand car Market[J].China Science and Technology Information,2012,22, 159-160.(in Chinese) 
[2]Liu Enhua, $\mathrm{Yu}$ Hongtao, $\mathrm{Wu}$ Qiuli. Study on the Factors which Influence the Domestic and Foreign second-hand car Trading Mechanism[j].Beijing Automotive Engineering,2011,1,1-4.(in chinese)

[3]LI Yan.Automatic Bus Stop Reporting System based on RFID Technology. Journal of Terahertz Science and Electronic Information Technology,2013,11(4),606-608.(in Chinese)

[4]LI Hong,WANG Linzhu, ZHANG Wen,WANG Songliang. Infant Safety Management System based on Integrated RFID and ZigBee network[J].CAAI Transactions on Intelligent System,2013,8(5), 465-471.(in Chinese)

[5]Yan Bo,Shi Ping. Intelligent Monitoring System for Aquiculture based on Internet of Things[J].2014,45(1),259-265. (in Chinese)

[6]Yang Chunduo,Li Jiangguo.The Design of Emergency Material Distribution Management System based on RFID Technology[J].Hoisting and Conveying Machinery,2011(5),23-26. (in Chinese)

[7]Shen Jinwei.Research on RFID Identity Authentication Technology[D].Guangdong University of Technology,2014. (in Chinese)

[8] He Li.RFID-based Localization and Tracking of Rom Operating Management System[D].University of Electronic Science and Technology,2013. (in Chinese)

[9]Wei Dengfeng.The Construction of RFID system of Information Network Based on Web Service[D]. Shanghai Normal University,2010. (in Chinese)

[10]Zhao Jin-long. The research of RFID Middleware Reader Redundancy Rrocessing Methods and Data Filtering Stategy[D].Lanzhou University of Technology,2013. (in Chinese) 